\title{
Corrigendum: Exploring population size changes using SNP frequency spectra
}

\section{Xiaoming Liu \& Yun-Xin Fu}

Nat Genet. 47, 555-559 (2015); published online 6 April 2015; corrected after print 14 August 2015

In the version of this article initially published, the authors neglected to acknowledge one of the funding sources for their study. The acknowledgements should have recognized support from Chinese NSF grant 91231120 in addition to the other funding sources listed. The error has been corrected in the HTML and PDF versions of the article.

\section{Corrigendum: Transcriptional activation of retrotransposons alters the expression of adjacent genes in wheat}

Khalil Kashkush, Moshe Feldman \& Avraham A. Levy

Nat. Genet. 33, 102-106 (2003); published online 16 December 2002; corrected after print 27 August 2015

In the version of this article initially published, Figure 2 was inappropriately enhanced. The original data have been restored to the figure. The authors state that all the display items in this publication are previously unpublished work and accurate representations of the experiments described. The error has been corrected in the HTML and PDF versions of the article. 